ORIGINAL ARTICLE

\title{
Study of Rhesus Genotype and Phenotype in Bangladeshi Population Attended in a Tertiary Care Hospital Transfusion Medicine
}

\author{
$*$ N Shil ${ }^{1}$, N Sultana ${ }^{2}$, S Sormin ${ }^{3}$ \\ ${ }^{1}$ Prof. Dr. Nittyananda Shil, Professor, Dept. of Transfusion Medicine, BSMMU \\ ${ }^{2}$ Dr. Nahid Sultana, Medical Officer, Dept. of Transfusion Medicine, BSMMU \\ ${ }^{3}$ Dr. Sonia Sormin, Medical Officer, Dept. of Transfusion Medicine, BSMMU \\ * Corresponding author
}

Date of submission: 08 November 2015

Date of acceptance:10 February 2016

\begin{abstract}
Background: The Rhesus Blood Group is one of the most important Blood Group like ABO. Exposure of Rhesus Negative individuals to Rhesus Positive Red Cells by Transfusion and/or Pregnancy is most likely to stimulate the production of Rhesus antibodies. These Antibodies may cause Haemolytic Diseases of Newborn (HDN) and Delayed Haemolytic Transfusion Reaction (DHTR.) Rh-antigens, mainly D, C ,E, e and small c are well developed before birth. $\mathrm{d}$ is not present or used hypothetically. The frequency of these antigens can be determined by using five different antisera; anti-D,-C, small c, -E and small e. Based on these Phenotype and Gene frequencies in a particular Population, the most probable Rh Genotype can be determined.

Methodology: This cross sectional comparative study was carried out with 1,000 randomized samples of both patient and donors in the department of Transfusion Medicine of Bangabandhu Sheikh Mujib Medical University (BSMMU). The eventual objective of the study was to determine the actual Rhesus phenotype-genotype frequency of Bangladeshi Native population. Sample was collected from both donor and patient. For each Test Saline and Anti Human Globulin Test (AHGT) were employed. Result: The most common genotype, we found, CDe/CDe i.e R1R1 (38.60\%) which is the most vulnerable genotype to be immunized, the next group in our study was CDe/cde $\mathrm{R} 1 \mathrm{r}(29.20 \%)$ and next category was CDe/Cde i.e. R1R2 (22.20\%). Very rare genotype in our study detected was cDE/cde i.e. R2R (1.90\%), cDE/cDE i.e. R2R2 (1.50\%) CDE/cDE i.e.R1Rz (0.60\%), cde/cde i.e. R0R0 $(0.60 \%)$. Among Rh (D) Negative samples genotypes found is cde/cde i.e. $\operatorname{rr}(4.50 \%$, and cde/cde i.e.r'r $(0.8 \%)$ and Cde/cdE i.e. rr" (0.10\%). Frequency distribution of genotype among male and female was also determined.
\end{abstract}

Conclusion: The findings may be used in formulating Clinical Transfusion Practice and to fourmule strategies to prevent Rh Sensitization, may thus also be useful in disputed paternity and genetic study in Bangladesh.

Key Words: Rhesus Antigens, Genotype, Phenotype, HDN, DHTR, Bangladeshi.

\section{Introduction}

Rhesus blood group system is highly immunogenic like $\mathrm{ABO}$ system. Most Rh (D) negative persons form anti D in any way specially either by transfusion or by transplacental hemorrhages. Not only D antigen but also other antigens of $\mathrm{Rh}$ system specially $\mathrm{C} \& \mathrm{E}$ are responsible. for the production of antibody is multitransfused patient. More than $80 \%$ of $\mathrm{Rh}(\mathrm{D})$ women form anti D after single exposure, further transfusion of $\mathrm{Rh}(\mathrm{D})$ positive blood may cause delayed Hemolytic transfused reaction. Moreover one in six cases of pregnant women with $\mathrm{Rh}(\mathrm{D})$ positive child may cause Hemolytic disease of newborn by inducing transplacental haemorrhage \& lysis of infant red cell. Rh antigens are also involved in the auto-immunization specifically of some of the warm antibodies of auto immune hemolytic anaemia. Outside D other antigens of Rh system may also immunize negative persons and may also cause HTR \& HDN but in small proportion.

In 1943, RA Fisher proposed that there were three closely linked genes Cc, Dd \& Ee which determine corresponding antithetical antigens ${ }^{1}$. He later proposed that the order of the genes was $\mathrm{DCE}^{2}$. Experience soon showed that such not occur. It was presumed that $d$ was an amorphic allele or is not present at all. There are five antigens at present, D, C, c, E \& e. Molecular biology 
technique has shown that there are only two genes. D which has no allele and a second gene $\mathrm{Cc}$ Ee which has many alleles. But it is convenient to use $d$ to indicate the absence in absence of $\mathrm{D}^{3}$.

The importance of determination of genotype is that when a woman form anti $\mathrm{D}$ in her serum it is important to know whether her partner is Dd or DD. If he is DD he can only be father of D positive offspring but if he is $\mathrm{Dd}$, will be $50 \%$ chance of being $\mathrm{D}$ positive child. One with $\mathrm{D}$ negative parents can not be DD. It is now recognized that there are three alternative antigens in set in Rh system. Every person inherits one set of these alternative antigens from each parent.

Each chromosome carries three of these genes situated closely together on the chromosome \& genes inherited as a unit \& not independent of each other ${ }^{4}$. The eight combinations of six $\mathrm{Rh}$ genes are such that each $\mathrm{Rh}$ chromosome has one $\mathrm{C}$, one $\mathrm{D}$, one $\mathrm{E}$ locus. The genotypes are expressed as pair of three genes inherited from each parents. Haplotypes are CDe, (R1), cDE (R2), cDe (R0), CDE (Rz), cde (r), cdE (r') and Cde $\left(\mathrm{r}^{\prime}\right)^{5}$. Haplotype frequencies among British Population are: $0.421,0.141,0.026,0.002,0.389,0.010$ and 0.012 respectively.

An $\mathrm{Rh}$ genotype therefore consists of any two of these chromosome arrangements. The fisher Race \& the Weiner nomenclature are used interchangeably. The Fisher Race terminology assumes inheritance of three closely linked genes \& Weiner terminology assumes inheritance of single gene from each parent which is a mosaic structure ${ }^{6}$, Another importance of genotype determination is that antibody develops when immunized in absence of the corresponding antigen i.e. gene ${ }^{7}$.

The completeness with which the Rh genotype can be determined depends on five antibodies: Anti-D, Anti-C, Anti-c, Anti-E \& Anti-e antisera are used for genotype study. Standardization of antisera is important. Day by day antisera is standardized8.

In the present study five standard antisera were used, probable genotype \& phenotype determined with their frequencies in Bangladeshi native population attending in a Tertiary Care Hospital, BSMMU, and compared with previous studies.

\section{Aim Of The Study}

The aim of the study is to identify actual Rh genotypephenotype in Bangladesh and thus help to formulate transfusion protocol to prevant alloimmunization \& strategy of transfusion in-patient with antibody. The study may also help in disputed paternity \& genetic study in Bangladesh.
TF Dipta, H Rahman, A Khatun et al

\section{Materials \& Methods}

1000 samples $(50.7 \%$ male \& $49.3 \%$ female, $94.6 \% \mathrm{Rh}$ D Positive, Sample mean age $36.36 \pm 0.077$ ) were randomized out of 1500 samples using calculator method $\&$ included in the present cross sectional study. Samples were of both patient and donor. The study was conducted in the dept. of Transfusion medicine within the period from 01.10 .2000 to 30.10 .2013 . Samples were tested fresh as possible in CPD solution with five standard monoclonal anti sera Anti-D, Anti E, Anti e (small), Anti C, Anti c (small) of Lorne Lab Uk. Tests were done according to manufacturers instruction. The results were recorded, Phenotypes, probable genotypes and their frequencies in percent determind. The result was compared with the results of previous three studies. The data was analyzed using SPSS varson-16 windows. $P$ value was set at $<0.05$ to show the test results significant.

\section{Results}

In the present study, out of 1000 samples (50.70 Percent male and 49.30 percent female of both donor and patient having mean age $36.36 \pm 0.077$ most samples wre Rh (D) Positive (94.60 percent). Most genotypes found were R1R1, R1r, R1R2 and rr with R1R1 in first position (38.6\%) and among Rh (D) negative rr (4.50\%) highest. This result was compared with previous three results by Haque (2000), Rahman (1992) and Das (1980). It was found that the result of present study is about same as that of Haque (2000) and the (1980). The result of Rahman et al (1992) seems to be misleading. Among Rh (D) Negative we found $\mathrm{rr}(4.5 \%)$ but the result of all previous studies are about half or below of the present study. There are some controversies within the said samples.

Table 1: Samples on Rh (D) Positive Negative and on gender $(\mathrm{n}-1000) \mathrm{P}<0.001$

\begin{tabular}{lccc}
\hline Donor & Number & Percentage & P \\
\hline Rh D+ve & 946 & $94.6 \%$ & $\mathrm{P}<0.04$ \\
Rh D-ve & 54 & $5.4 \%$ & $\mathrm{P}<0.05$ \\
Male & 507 & $50.70 \%$ & $\mathrm{P}<0.001$ \\
Female & 493 & $49.30 \%$ & $\mathrm{P}<0.001$ \\
\hline
\end{tabular}

* $94.60 \%$ of samples are Rh D+ve. Male \& female are almost equal. 
Study of Rhesus Genotype and Phenotype in Bangladeshi Population

Table 2: Rhesus Phenotype and most probable Genotype found in study.

\begin{tabular}{cccccll}
\hline AntiC & AntiD & AntiE & Antic & Anti & Phenotype & $\begin{array}{l}\text { Most Probable } \\
\text { Genotype }\end{array}$ \\
\hline+ & + & - & - & + & CCDee & $\mathrm{R} 1 \mathrm{R} 1$ \\
+ & + & - & + & + & CcDee & $\mathrm{R} 1 \mathrm{r}$ \\
+ & + & + & + & + & CcDEe & $\mathrm{R} 1 \mathrm{R} 2$ \\
- & + & + & + & + & ccDEe & $\mathrm{R}_{2} \mathrm{r}$ \\
- & + & + & + & - & ccDEE & $\mathrm{R} 1 \mathrm{R} 2$ \\
+ & + & + & - & + & CCDEe & $\mathrm{R} 1 \mathrm{R} Z$ \\
- & + & - & + & + & ccDee & $\mathrm{R} 0 \mathrm{R} 0$ \\
+ & - & - & + & + & ccee & $\mathrm{r} \mathrm{r}$ \\
- & - & - & + & + & Ccee & $\mathrm{r}$ r \\
- & - & + & + & + & ccEe & $\mathrm{rr}{ }^{\prime \prime}$ \\
\hline
\end{tabular}

* Most genotypes are R1R1, R1r, R1R2 and rr.

Table 3: Genotype frequency found in study $(\mathrm{n}-1000) \mathrm{P}<0.005$

\begin{tabular}{lccc}
\hline Fisher-Race & Weiner & No of sample & Frequency \\
\hline $\mathrm{CDe} / \mathrm{CDe}$ & $\mathrm{R}_{1} \mathrm{R}_{1}$ & 386 & 38.60 \\
$\mathrm{CDe} / \mathrm{cde}$ & $\mathrm{R} 1 \mathrm{r}$ & 292 & 29.20 \\
$\mathrm{CDe} / \mathrm{cDE}$ & $\mathrm{R}_{1} \mathrm{R}_{2}$ & 222 & 22.20 \\
$\mathrm{E}$ & $\mathrm{R}_{2} \mathrm{r}$ & 19 & 1.9 \\
$\mathrm{cDE} / \mathrm{cDE}$ & $\mathrm{R}_{2} \mathrm{R}_{2}$ & 15 & 1.5 \\
$\mathrm{CDe} / \mathrm{CDE}$ & $\mathrm{R}_{1} \mathrm{R}_{2}$ & 06 & 0.6 \\
$\mathrm{cDe} / \mathrm{cDe}$ & $\mathrm{R}_{\mathrm{O}} \mathrm{R}_{\mathrm{O}}$ & 06 & 0.6 \\
$\mathrm{cde} / \mathrm{cde}$ & $\mathrm{rr}$ & 45 & 4.5 \\
$\mathrm{Cde} / \mathrm{cde}$ & $\mathrm{r} \mathrm{r}_{\mathrm{r}}$ & 08 & 0.8 \\
$\mathrm{Cde} / \mathrm{cdE}$ & $\mathrm{r} \mathrm{r}^{\prime}$ & 01 & 0.1 \\
\hline
\end{tabular}

* R1R1 is 38.60 percent \& R1r is 29.20 Percent.

Table 4: Genotype Frequencies among male and female $(\mathrm{n}=1000) \mathrm{P}<0.05$

\begin{tabular}{lllllll}
\hline $\begin{array}{c}\text { No of } \\
\text { sample }\end{array}$ & $\begin{array}{c}\text { Geno } \\
\text { type }\end{array}$ & $\begin{array}{c}\text { Genotype } \\
\text { Frequency }\end{array}$ & $\begin{array}{c}\text { Male } \\
\text { Sample }\end{array}$ & $\begin{array}{c}\text { Geno } \\
\text { type } \\
\text { Freq } \\
\text { uency }\end{array}$ & $\begin{array}{c}\text { Female } \\
\text { Sample }\end{array}$ & $\begin{array}{c}\text { Geno } \\
\text { type } \\
\text { Freq } \\
\text { uency }\end{array}$ \\
\hline 386 & $\mathrm{R} 1 \mathrm{R}_{1}$ & 38.60 & 200 & 39.44 & 186 & 37.73 \\
292 & $\mathrm{R} 1 \mathrm{r}$ & 29.20 & 142 & 28.0 & 150 & 30.43 \\
222 & $\mathrm{R} \mathrm{R}_{2}$ & 22.20 & 113 & 22.28 & 109 & 22.11 \\
19 & $\mathrm{R} 2$ & 1.9 & 11 & 2.16 & 8 & 1.63 \\
15 & $\mathrm{R} 2 \mathrm{R}_{2}$ & 1.5 & 8 & 1.57 & 7 & 1.42 \\
06 & $\mathrm{R} 1 \mathrm{R}_{\mathrm{Z}}$ & 0.6 & 4 & 0.78 & 2 & 0.40 \\
06 & $\mathrm{R} \mathrm{R}_{0}$ & 0.6 & 3 & 0.59 & 3 & 0.60 \\
45 & $\mathrm{Rr}$ & 4.5 & 22 & 4.33 & 23 & 4.67 \\
08 & $\mathrm{r}{ }^{\prime} \mathrm{r}$ & 0.8 & 4 & 0.78 & 4 & 0.81 \\
01 & $\mathrm{rr}$ " & 0.1 & 0 & 0 & 1 & 0.20 \\
1000 & & $507(50.7 \%)$ & & 100 & $493(49.3 \%)$ & 100 \\
\hline
\end{tabular}

* R1R1 in male is $39.44 \%$ \& $37.73 \%$ female.
Table 5: Genotype Frequency in different study:

\begin{tabular}{lcccc}
\hline Genotype & $\begin{array}{c}\text { Das et al } \\
\mathbf{1 9 8 0} 9\end{array}$ & $\begin{array}{c}\text { Rahman } \\
\text { et a1 } \\
\mathbf{1 9 9 2}\end{array}$ & $\begin{array}{c}\text { Haque } \\
\text { et al 11 } \\
\mathbf{2 0 0 0}\end{array}$ & $\begin{array}{c}\text { Present } \\
\text { study } \\
\text { Shil 2014 }\end{array}$ \\
\hline Rh (D) & & & & \\
Positive & & & & \\
R1r & 30.89 & 26.25 & 33.20 & 29.20 \\
R1R1 & 46.75 & 24.06 & 37.00 & 38.60 \\
R1R2 & 11.99 & 39.75 & 18.60 & 22.20 \\
R2r & 5.89 & 2.06 & 4.40 & 1.90 \\
R2R2 & 0 & 0.06 & 0.20 & 1.50 \\
R1Rz & 0.2 & 0.50 & 0.80 & 0.60 \\
RoRo & 0 & 1.75 & 0 & 0.60 \\
Rh (D) & & & & \\
Negative & & & & \\
& 2.85 & 1.75 & 2.80 & 4.50 \\
r'r & 0.20 & 0.125 & 0.20 & 0.80 \\
rtr' & 0.20 & 0 & 0.20 & 0.10 \\
& & & & \\
\hline
\end{tabular}

* In the present study R1R1 is 38.60 which match with Haque (2000) \& is highest.

\section{Discussion}

The results of the study for Rhesus Phenotype, Genotype and their Frequencies shows the most frequent probable Genotype being R1R1 among Bangladeshi population and it is $386(38.60 \%)$. Least frequency was found in $\mathrm{rr}^{\prime \prime}$ and it is $0.1 \%$ among 1000 random blood samples examined. Within 1000 samples Rh D positive samples were 966 (96.6\%) and negative 54 (5.4\%). Most frequent $\mathrm{Rh} \mathrm{D}$ positive genotype was maximum among male samples 200 (39.44\%). Second frequent genotype was R1r 292 (29.20\%) and was found maximum among female samples $150(30.42 \%)$. Third frequent genotype was found R1R2 and was $220(22.20 \%)$ and it was maximum among male 113 (22.28\%). Rh D Negative genotype $\mathrm{rr}$ is frequent and it is $4.5 \%$. Other Two negative genotype found was r'r $0.8 \%$ and $\mathrm{rr}^{\prime \prime} 0.1 \%$. Highest among female $4.53 \%$. It may be pointed out that there are more than one probability of genotypes. Most probable option is taken as genotype \& is expressed as phenotype frequency. Another fact is that no anti $d$ is present \& so no detection of $\mathrm{r} 0$. The probability of genotype also depends upon the frequency of gene. So various phenotype can be guessed as first probable genotype. By using family studies in addition may be possible to determine genotype perfectly.

Various studies are available to compare the result of present study- one among Bengali Hindu population \& two among Bangladeshi population. The question generally arise whether any genetic difference between Bengali Hindu \& Bengali Muslim population exist. But 
the result is different. Highest frequency found in present study R1R1 was also found among Bengali Hindu9 population. But R1R2 was highest in Bangladeshi population10. It should be realized that there are wide racial differences between frequencies of the Rh gene complex 7,8. In the present study genotype R1R1 was found highest and was also found highest in study done in 2000 by Haque et al11. The present study was done with mixed Hindu \& Muslim (Bengali) population of Bangladesh although most cases are Muslims. The study seems more accurate in racial consideration. Bengali population seems to be of same genetic origin but genetic origin of Bangladeshi may be different. The variation of genotype in previous study \& present Bangladeshi Bengali study seems to be due to the difference of five antisera used. Studies were done in 1980 \& 1992 or before no monoclonal antibody was available. Now a day's antisera have developed \& standardized much. Test in the present study was done with monoclonal antibodies. No $\mathrm{Du}$ or $\mathrm{D}$ variant was identified.

\section{Conclusion}

All multi-Transfused should be genotyped and phenotyped along with $\mathrm{ABO}$ Grouping to prevent immunization. In Bangladesh genotype R1R1 is highest.

\section{Acknowledgement}

Special thanks to all staff of transfusion medicine department, BSMMU for their work \& help in conducting this study.

Conflict of Interest: The authors have no conflict of interest to any body.

\section{References}

1. Race RR. An incomplete antibody in Human serum. Nature( London); 1944, 153: 771-7.

2. Fisher RA, Race RR. Rhesus Gene Frequency in Britain. Nature (London); 1946, 157: 48-9

3. PL Mollison. Blood Transfusion in Clinical Medicine. 10th. Edition, Blackwell Publishing. Page 164.

4. PL Mollison, Blood Transfusion in Clinical Medicine, 10th. Edition, Blackwell Publishing page 163.

5. Fisher RA. Race RR. An incomplete antibody in Human serum 1946. Nature(London); 158: 771-772.

6. PL Mollison. Blood Transfusion in Clinical Medicine, 10th. Edition, Blackwell Publishing page 165.

7. Maurant A.E. Rh Phenotype \& Fisher's CDE notation: 1949. Nature (London) 163: 913.

8. Maurant AE, The Distribution of Human Blood Group And other Biological polymorphism, 2nd edition, Oxford University press, 1976.

9. Das KK, Sen. NN. Rhesus Gene Frequency in Bengali Hindu Population. Transfusion Bulletin, Indian Society of Blood Transfusion \& Immuno-haematology, 1980; 1:13 .

10. Rahman M, Abdullah AZM, Nandi CK and Mollah MAA et al. Rhesus Genotype in Bengali Population. BMRC Bulletin, 1992;18 (2) : 89-94.

11. Haque K.M.G, Yousuf R. Determination of Rhesus Phenotype- Genotype frequencies in Bangladeshi people, Bangladesh Journal of Pathology, 2000; 15(2): 15-19. 